\title{
MOVIMIENTO GRSB
}

OSWALDO TERREROS

\section{Sobre el proyecto:}

El Movimiento GRSB (2009) es un lugar donde conviven diferentes pensamientos políticos para capitalizar simbólicamente este movimiento. A partir de los enunciados de propaganda política y una estructura visual muy identificable.

Departamento de Investigación de Gráfica y Militancia del Movimiento GRSB (2014), trabaja sobre la historia de la gráfica política. Esta travesía inicia con la "Campaña nacional por la concientización del progreso en el 2014 y luego empiezo a trabajar otros proyectos, entre estos se encuentra: "Cerrenismo en el Ecuador". Este proyecto trabaja sobre la vida de Eusebio Macías Suárez fundador del Movimiento C. R. N. (Cruzada Reivindicadora Nacional) y su campańa política en 1956. Este proyecto es la simulación de las intervenciones de Eusebio en la vía pública. Otro proyecto se llama Reactivación, Repotenciación y Revitalización de Asociaciones Obreras es un proyecto que retoma estéticas de manifestación obrera de los ańos 50's como si no hubieran dejado de producirse, asimilar una estética, producirla y reinsertarla en paisaje urbano, donde opera la manifestación obrera.

Palabras clave: muralismo, multitud, obreros, simulacro, modernidad

\section{About the project:}

GRSB Movement (2009) is a place where different political thoughts coexist to capitalize symbolically, based on political propaganda statements created on highly recognizable visual structure.

The Office of Graphic Research and Militancy at the GRSB Movement (2014), works on the history of political images. This journey begins at the "National Campaign for the Awareness of Progress" (2014), later there were other projects like: "Cerrenismo en el Ecuador". This project research in life of Eusebio latical he were onis Machs Su. This proect reproduce campaign. This project reproduces Eusebio's interventions in different public highways. Another project called "Reactivación, Repotenciación y Revitalización de Asociaciones Obreras" which takes worker manifestation aesthetics in the 50 's, as if they haven't changed, reintegrating it into the urban landscape.

Key words: muralism, crowd, workers, simulacrum, modernity

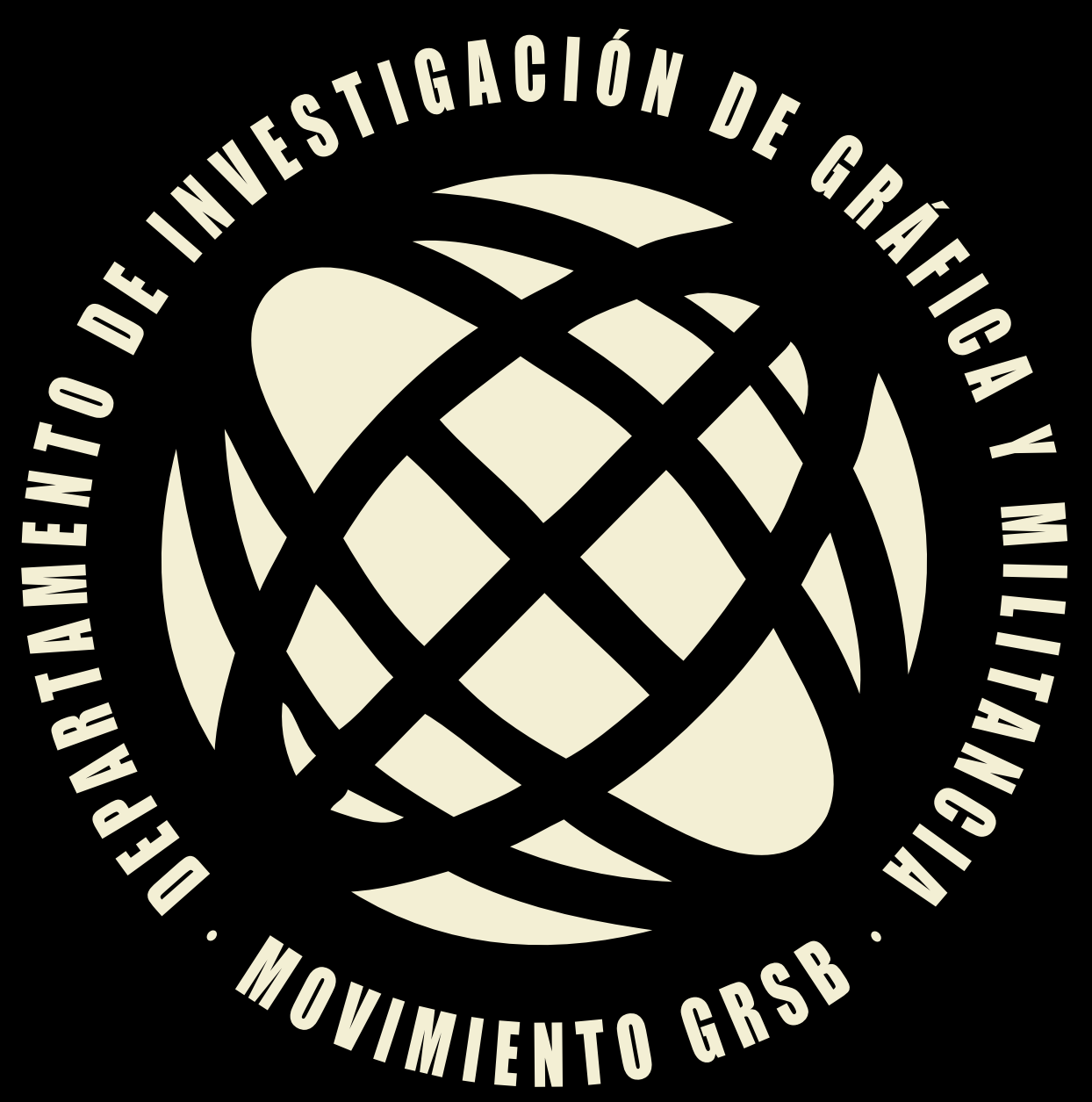

Autor:

Oswaldo Terreros. Estudié Publicidad y Artes Visuales. Trabajo como Director de Arte y toda mi producción artística recae sobre el paraguas del Movimiento GRSB (Gráfica Revolucionaria para produción a

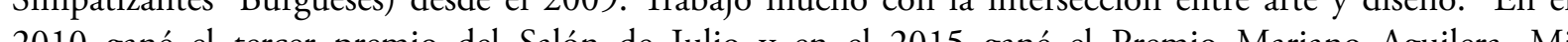
2010 gané el tercer premio del Salón de Julio y en el 2015 gané el Premio Mariano Aguilera. Mi producción ha sido publicada por diferentes editoiales: Lain Amiencan Graphic Design (Thana, 2006). Latin American Graphic Design (Taschen, 2008). Logo Design Vol. 2 (Taschen, 2009). Logo Design Vol. 3 (Taschen, 2011). Los afiches sociopolíticos del Movimiento GRSB fueron publicados en APD V (Asia-Pacific Design) (editorial SAN DU, 2009) and EXCELLENT (International Design Yearbook) (editorial MDX, 2011). He estado presente tres veces en la Bienal Iberoamericana de Diseńo con sede en Madrid, en la segunda edición en el ano 2010 realizo el Gran Encuentro Capitulo 3: Utopia Desplazada. 


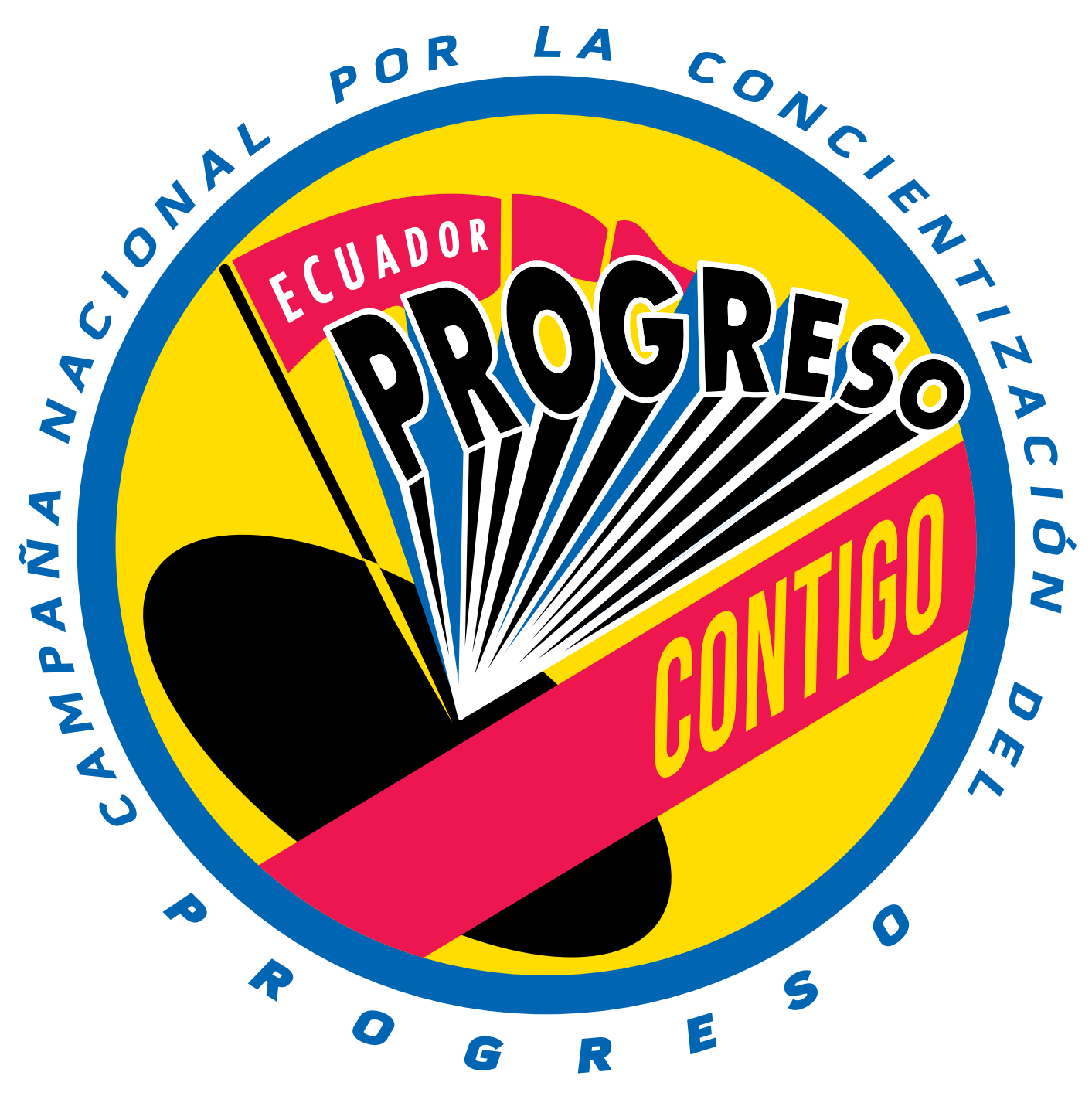




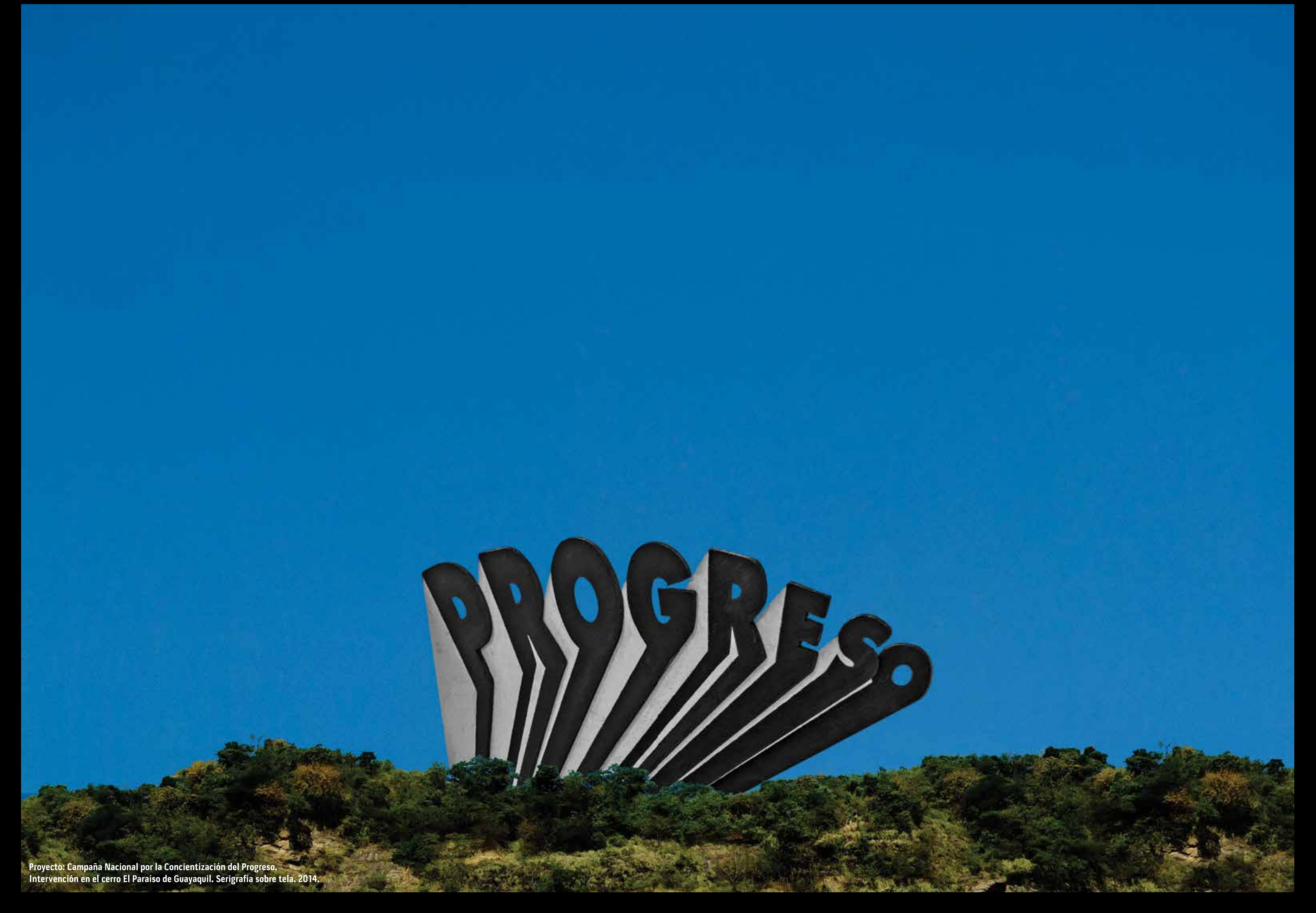




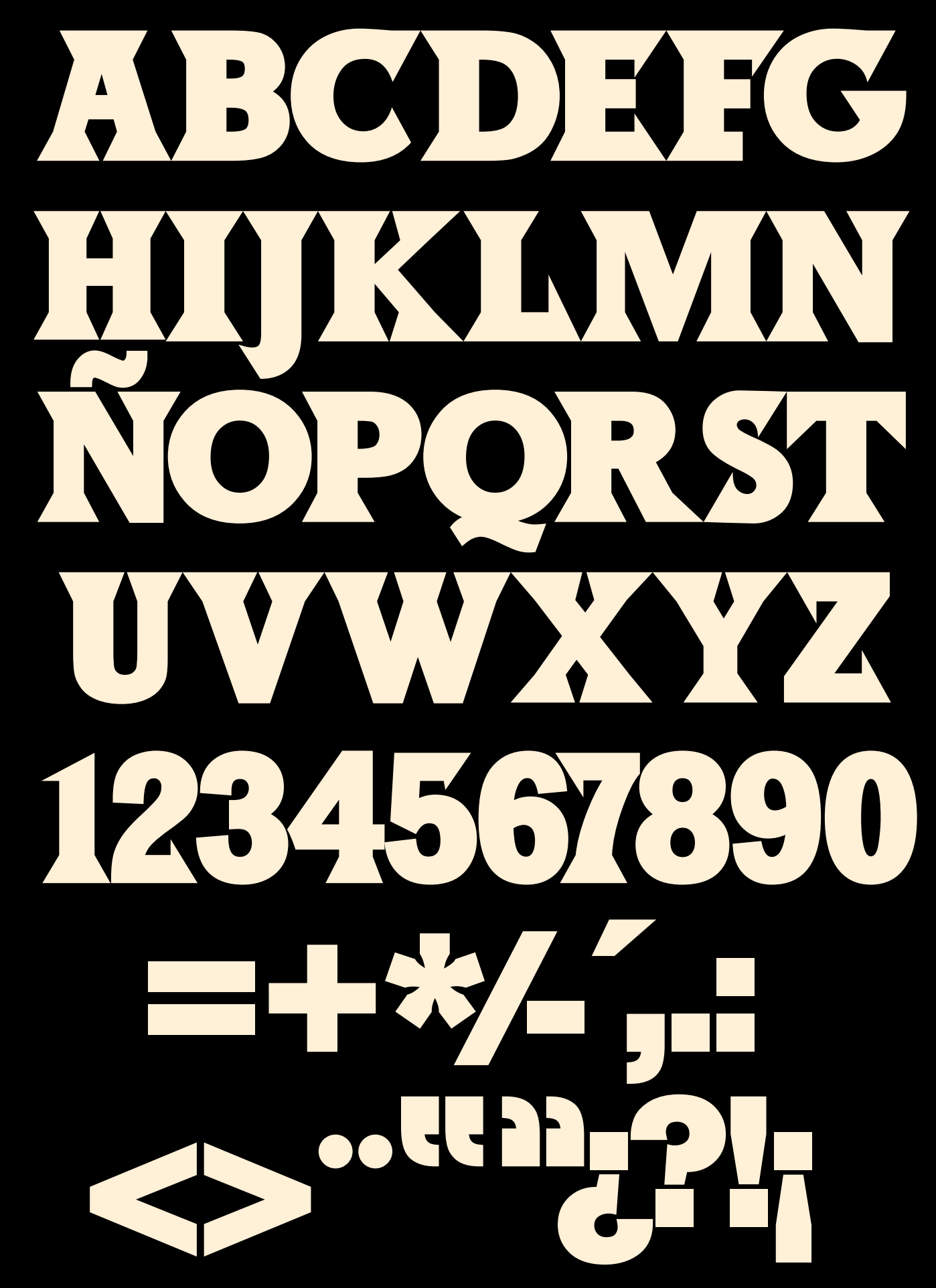




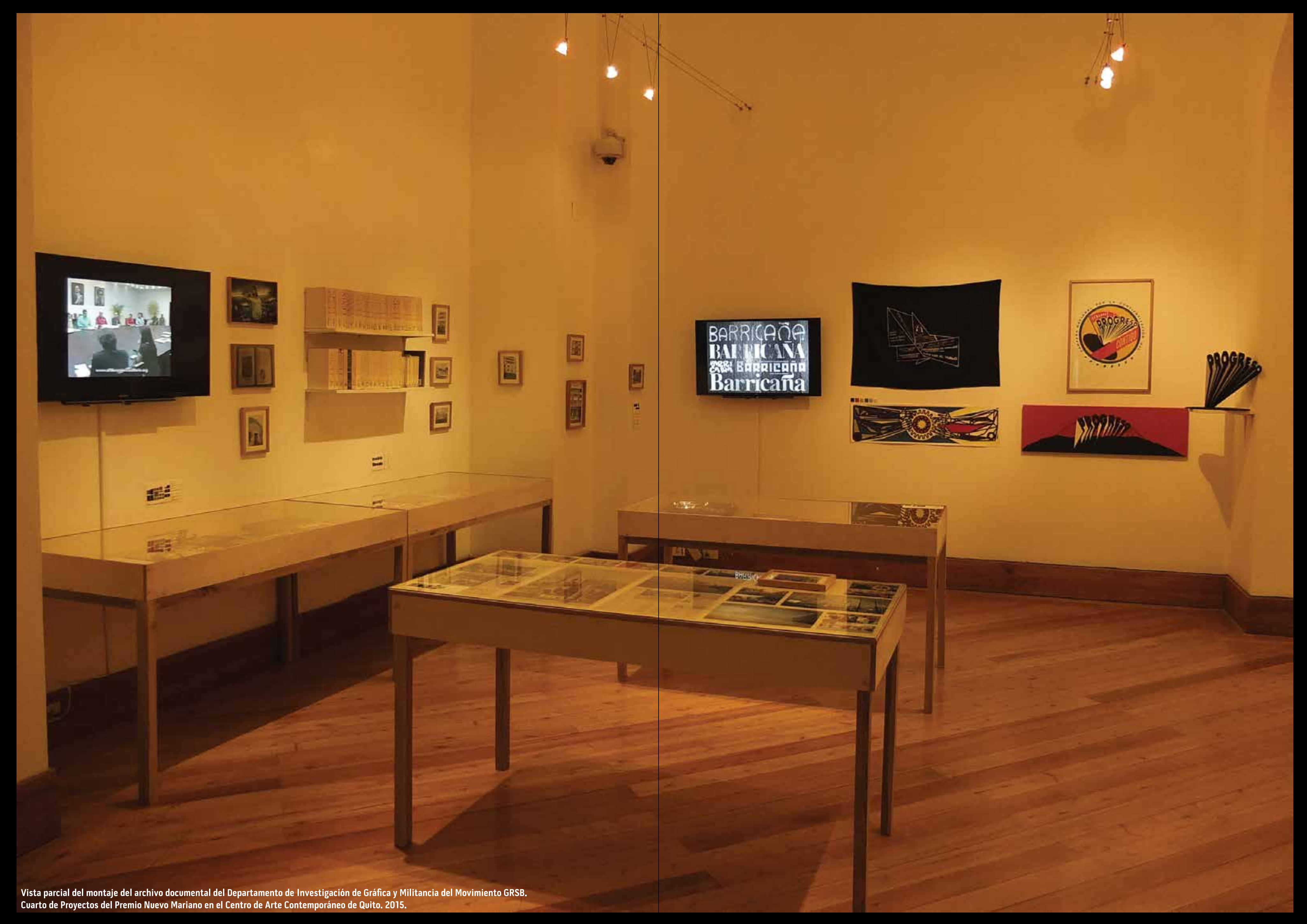




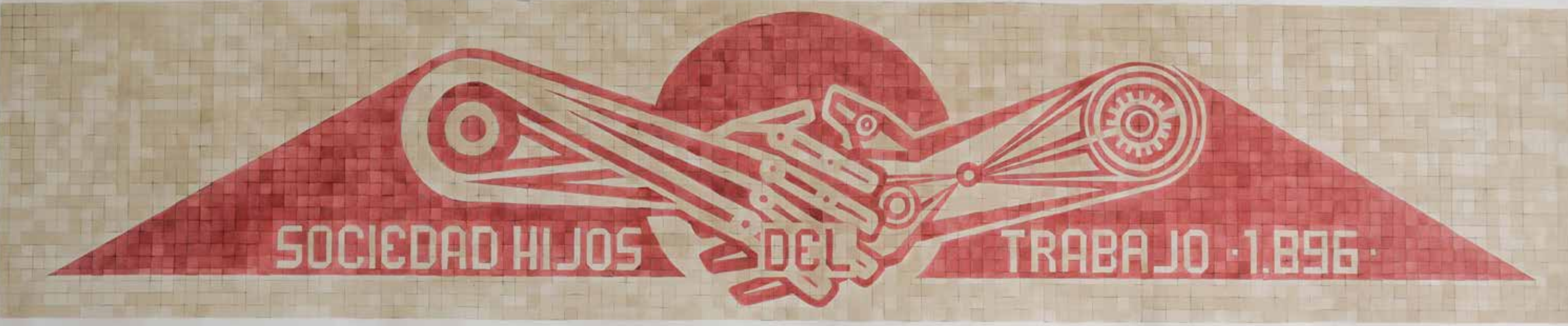




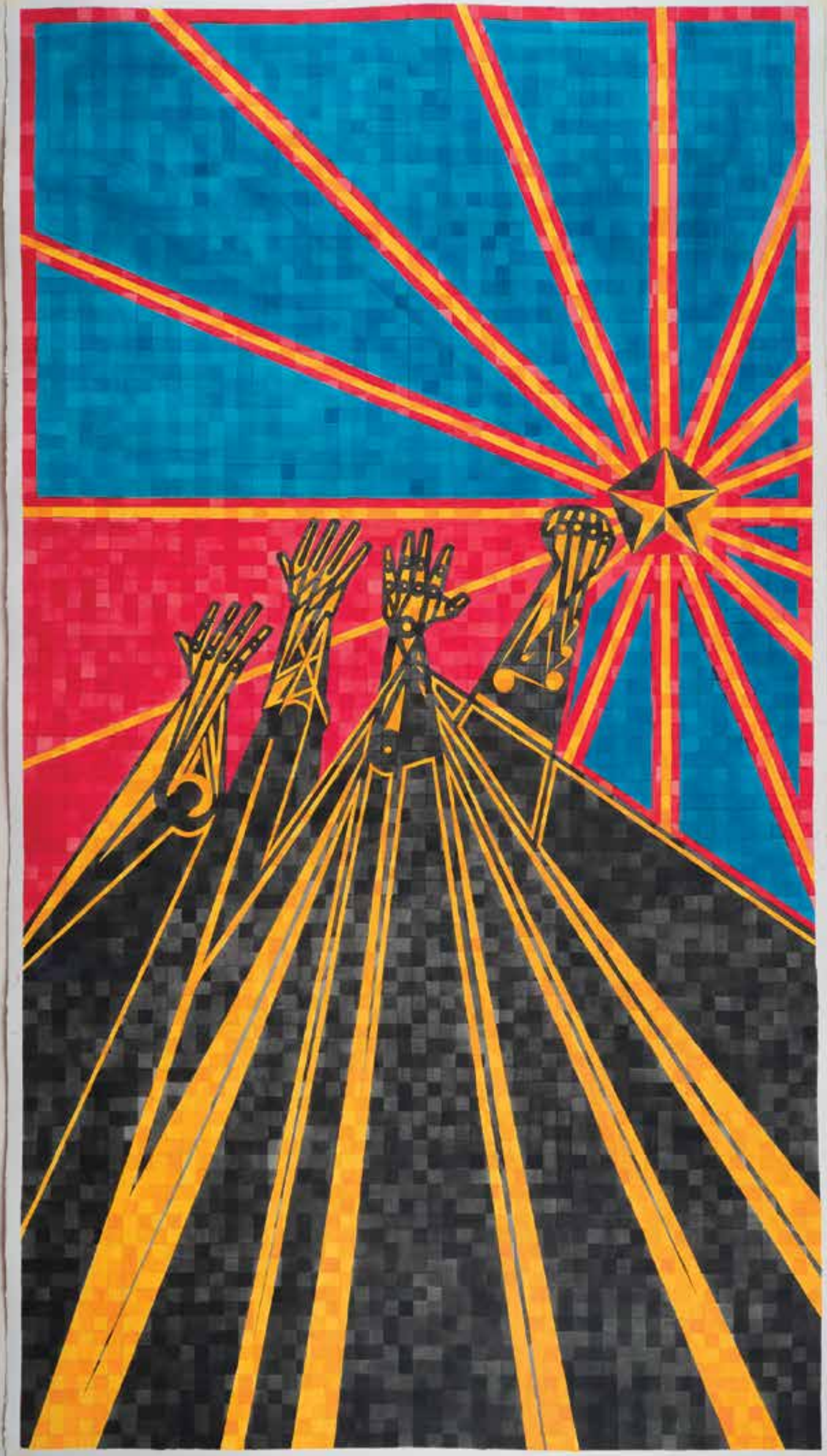



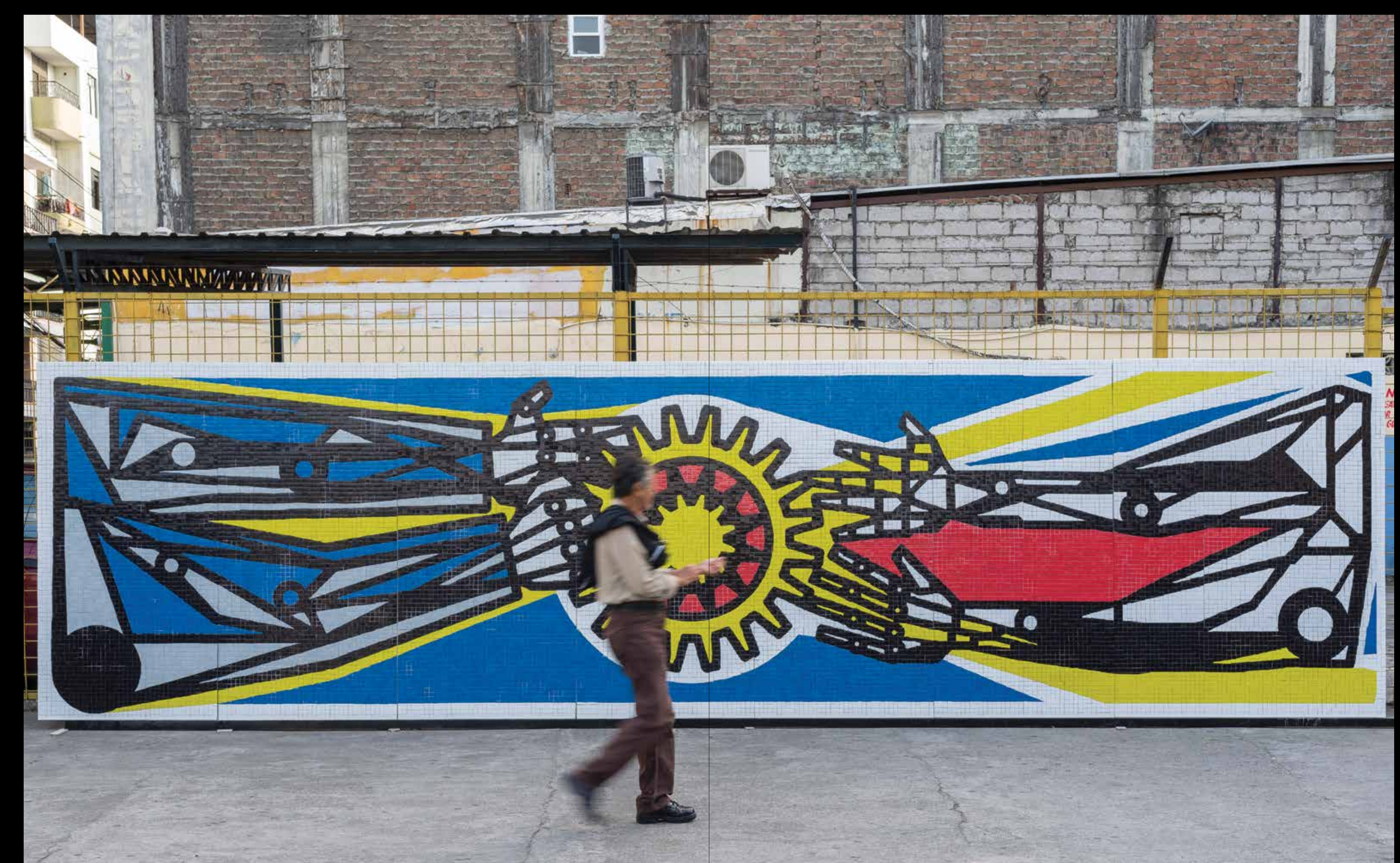